\title{
Evaluation of Some Biochemical Changes in Diabetic Patients M.A.EI-desoky ${ }^{1}$; A.E.Amin ${ }^{1}$;M.O.El-refai ${ }^{1}$;R.J.Farid ${ }^{2}$;A.A.Labib ${ }^{3}$ \\ 1-Department of Chemistry,Biochemistry Division, Faculty of Science, Cairo University. 2-Department of Clinical Pathology, Faculty of Medicine, Cairo University. 3-M.Sc candidate, Faculty of Science, Cairo University.
}

\begin{abstract}
Patients and methods: The present study consisted of 50 subjects were classified into three groups ; Group (GI) Control group consisted of 10 clinically healthy adult subjects of both sexes free from any liver, kidney or cardiovascular diseases .

Group (GII) diabetes mellitus type 1 consisted of 20 patients of both sexes.

Group (GIII) diabetes mellitus type 1 with nephropathy consisted of 20 patients of both sexes . All subjects were undergo to the following investigated parameters; Ascorbic acid (vitamin C) ,Catalase ,Total antioxidant capacity, Aldolase and Pyruvate kinase enzyme.

Results: vitamins $C$, catalase, total antioxidant capacity enzymes were highly significant decreased $(\mathrm{P}<0$. 01 ) in diabetes mellitus type 1 (GII) and diabetes mellitus type 1 with nephropathy (GIII) when compared to the control group. Adolase activity was highly significant increased $(\mathrm{P}<0.01)$ in diabetes mellitus type 1 with nephropathy (GIII) when compared to the control group. Pyruvate Kinase activity was highly significant increased $(\mathrm{P}<0.01)$ in diabetes mellitus type 1 (GII) when compared to the control group . Conclusion: The antioxidant and enzymes can be used for follow up in patients suffering from diabetes mellitus type 1 and predict other complications.

Key words: Diabetes Mellitus, diabeteic nephropathy, Ascorbic acid, Catalase enzyme, Total antioxidant capacity, Aldolase enzyme and Pyruvate kinase enzyme.
\end{abstract}

\section{Introduction}

Diabetes mellitus is a major public health problem in the developed as well as developing countries. It is ranked seventh among the leading causes of death, and third when its fatal complications are taken in to account (1). The strict division into type 1 and type 2 diabetes based on an autoimmune etiology versus a primarily metabolic pathology (2).

Type 1 diabetes has been previously known as insulin-dependent or juvenile-onset diabetes. It results from the destruction of pancreatic beta cells which leads to insulin deficiency and lifelong dependency on insulin therapy (3) The variation in age at onset could be indicative of disease heterogeneity, with different mechanisms leading to $\beta$ cell destruction in childhood onset versus adult onset diabetes (4)

Diabetic nephropathy is the leading cause of chronic renal disease in patients starting renal replacement therapy (5). Diabetic nephropathy has been classically defined as increased protein excretion in urine. Early stage is characterized by a small increase in urinary albumin excretion (UAE), also called microalbuminuria or incipient diabetic nephropathy (5) .More advanced disease is defined by the presence of macroalbuminuria or proteinuria. The latter is classically named overt diabetic nephropathy. In most cases, proteinuria and decreased glomerular filtration rate (GFR) occur in parallel. Traditionally, GFR has been expected to decrease when proteinuria is established, but not before. However, it is clear today that some subjects could have diabetic nephropathy without increased UAE (6).

L-ascorbic acid, also known as Vitamin $\mathrm{C}$, is a water-soluble vitamin that is naturally present in some foods, added to others, and available as a dietary supplement (7). vitamin $\mathrm{C}$ is well known for its antioxidant activity, acting as a reducing agent to reverse oxidation in liquids. When there are more free radicals (reactive oxygen species, ROS) in the human body than antioxidants, the condition is called oxidative stress (8). The roles of vitamin $\mathrm{C}$ as an aldose reductase inhibitor and a water soluble antioxidant in body fluids are potentially very important as adjuncts to tight glycemic control in the management of diabetes (9).

Catalase is a common enzyme found in nearly all living organisms exposed to oxygen (10). It is a tetrameric enzyme consisting of four identical, tetrahedrally arranged subunits of $60 \mathrm{kDa}$, each containing in its active center a heme group and Nicotinamide adenine dinucleotide phosphate NADPH. (11)

An antioxidant is a substance capable of preventing or slowing the oxidation of other molecules. Generally, an antioxidant can protect against metal toxicity by trapping free radicals thus terminating the chain reaction, by chelating metal ion and preventing the reaction with 
reactive oxygen species or by chelating metal and maintaining it in a redox state leading to its incompetency to reduce molecular oxygen. Substances which protect biomolecules from free radical-mediated damage both in vivo and in vitro fall under this category (12).

Aldolases are a group of enzymes which are able to catalyse the aldol reaction in a reversible manner. Like all enzymes, this occurs with great region and stereoselectivity, under very mild conditions (13).

Pyruvate Kinase is an enzyme that is involved in glycolysis. Pyruvate kinase's function is to catalyze the last step of glycolysis; thereby, generating the second ATP of glycolysis and pyruvate. It is able to catalyze this step by transferring the phosphate group from phosphoenolpyruvate (PEP) to adenosine diphosphate (ADP) (14).

\section{Material and Methods}

\section{Subjects and design:}

The present study consisted of 50 subjects were obtained from New Kasr El Aini Teaching Hospital, Cairo, Egypt.

This work was carried out at Faculty of Science, Cairo University in period from Mar.2012 till Sep.2012.subjects were classified into three groups as follow; Group (I): Control group (GI), consisted of 10 clinically healthy adult subjects of both sexes 5 males and 5 females free from any liver, kidney or cardiovascular diseases, were aged from 25-35 years (mean=29.8). Group (II): diabetes mellitus type 1 (GII), consisted of 20 patients of both sexes 10 males and 10 females were aged from 28-37 years (mean=32.2). Group (III): diabetes mellitus type 1 with nephropathy (GIII), consisted of 20 patients of both sexes 10 males and 10 females were aged from 32-40 years (mean=35.7).

Blood samples from all studied groups were collected for determination the level of Ascorbic acid (vitamin C) ,Catalase ,Total antioxidant capacity, Aldolase and Pyruvate kinase enzyme.

\section{Specimens:}

\section{A- Serum:}

$5 \mathrm{ml}$ of blood were collected into tubes, allowed to clot at $37^{\circ} \mathrm{C}$ in water bath and centrifuged at $4000 \mathrm{rpm}$ for 20 minutes. Serum was separated and utilized for the enzyme assays.

\section{B-Plasma :}

Blood was collected into heparinized tubes and centrifuged at $4000 \mathrm{rpm}$ for 15 minutes and the plasma was collected for assaying .

Ascorbic acid (vitamin C) level colorimetric method Principle:(15).
Redox reaction of ascorbate with 2,6dichlorophenol indophenol in acid solution involves reduction of this dye to a colourless leucobase while ascorbate is oxidized to dehydroascorbate. In blood and urine the vitamin is mainly present as ascorbate in fresh samples.

\section{Catalase Activity colorimetric method} Principle:(16).

Catalase reacts with a known quantity of $\mathrm{H}_{2} \mathrm{O}_{2}$. The reaction is stopped after exactly one minute with catalase inhibitor. In the presence of peroxidase (HRP), remaining $\mathrm{H}_{2} \mathrm{O}_{2}$ reacts with 3,5-Dichloro -2-hydroxybenzene sulfonic acid (DHBS) and 4-aminophenazone (AAP) to form a chromophore with a color intensity inversely proportional to the amount of catalase in the original sample.

Total antioxidant capacity colorimetric method Principle: (17).

The determination of the antioxidative capacity is performed by the reaction of antioxidants in the sample with a defined amount of exogenously provide hydrogen peroxide $\left(\mathrm{H}_{2} \mathrm{O}_{2}\right)$ The antioxidants in the sample eliminate a certain amount of the provided hydrogen peroxide. The residual $\mathrm{H}_{2} \mathrm{O}_{2}$ is determined colorimetrically by an enzymatic reaction which envolves the conversion of 3,5 dichloro -2- hydroxy benzensulphonate to a colored product.

Aldolase activity kinetic method Principle: (18).

This reagent determines the aldolase activity in vitro in the presence of substrate D-Fructose-1,6bisphosphate and of the enzyme which manage the ancillary reaction, TIM (triosephosphate isomerase)-GDH(glycerol-3p-dehydrogenase)-

LDH(lactate dehydrogenase), at the end the aldolase change NADH to NAD, The decrease of absorbance of NADH, for oxidation to NAD, is proportional to the activity of the aldolase in the sample.

Pyruvate kinase activity kinetic method Principle: (18).

Pyruvate kinase in the sample catalyzes the reaction between ADP and PEP (phosphoenolpyruvate), forming pyruvate. The lactate dehydrogenase (LDH) in the system catalyze the reaction between pyruvate and $\mathrm{NADH}$, giving lactic acid and NAD. The decrease of absorbance in $10 \mathrm{~min}$ at $340 \mathrm{~nm}$, due to the oxidation of NADH is proportional at the activity of the PK in the sample.

\section{Statistics:}

All statistical analyses were performed using GraphPad Prism version 5.01 software package (GraphPad software,Inc.CA,USA). Data are expressed as mean \pm standard deviation (S.D) to 
determine differences between groups and analysis of variance (ANOVA).The level of statistical significance was set at probability $\mathrm{P} \leq$ 0.05 .

\section{Results}

\section{Ascorbic acid (vitamin C)}

Plasma Ascorbic acid level in patients of diabetes mellitus type 1 (GII) and patients of diabetes mellitus type I with nephropathy (GIII) was highly significant decrease $(\mathrm{P}<0.001)$ when compared to control group. Plasma Ascorbic acid level in patients of diabetes mellitus type I with nephropathy (GIII) was highly significant decrease $(\mathrm{P}<0.001)$ when compared to diabetes mellitus type 1 (GII).as shown in figure 1 .

\section{Catalase Activity}

Plasma Catalase activity in diabetes mellitus type 1 (GII) was highly significant decrease $(\mathrm{P}<0.001)$ in patients of diabetes mellitus type 1 (GII) and patients of diabetes mellitus type I with nephropathy (GIII) when compared to control group. Plasma Catalase activity in patients of diabetes mellitus type I with nephropathy (GIII) was highly significant decrease $(\mathrm{P}<0.001)$ when compared to diabetes mellitus type 1 (GII). as shown in figure 2.

\section{Total antioxidant capacity}

Plasma Total antioxidant capacity in patients of diabetes mellitus type 1 (GII) and patients of diabetes mellitus type I with nephropathy (GIII) was highly significant decrease $(\mathrm{P}<0.001)$ when compared to control group. But Plasma Total antioxidant capacity in patients of diabetes mellitus type I with nephropathy (GIII) was not significant decrease as compared with diabetes mellitus type 1 (GII). as shown in figure 3 .

\section{Aldolase activity}

Serum Aldolase activity in patients of diabetes mellitus type 1 (GII) was in Significant increase $(\mathrm{P}>0.05)$ when compared to control group, But in patients of diabetes mellitus type I with nephropathy (GIII) was highly significant increase $(\mathrm{P}<0.001)$ when compared to control group. Serum Aldolase activity in patients of diabetes mellitus type I with nephropathy (GIII) was highly significant increase $(\mathrm{P}<0.001)$ when compared to diabetes mellitus type 1 (GII). as shown in figure 4.

\section{Pyruvate kinase activity}

Serum Pyruvate kinase activity in patients of diabetes mellitus type 1 (GII) was highly significant increase $(\mathrm{P}<0.001)$ when compared to control group, But in patients of diabetes mellitus type I with nephropathy (GIII) was less significant increase $(\mathrm{P}<0$.05) when compared to control group . Serum Pyruvate kinase activity in patients of diabetes mellitus type 1(GII) was significant increase $(\mathrm{P}<0$.05) when compared with diabetes mellitus type I with nephropathy (GIII). as shown in figure 5 .

\section{Discussion}

Oxidation reactions can produce free radicals. In turn, these radicals can start chain reactions. When the chain reaction occurs in a cell, it can cause damage or death to the cell. Antioxidants terminate these chain reactions by removing free radical intermediates, and inhibit other oxidation reactions. They do this by being oxidized themselves, so antioxidants are often reducing agents (19). Among them, bilirubin, uric acid and protein thiols are the major endogenous antioxidants, while vitamins $\mathrm{C}$ and $\mathrm{E}$, as well as a number of food-derived (poly)aromatic substances, belonging to stilbens, flavonoids and phenolic acids, are the main classes of nutritional antioxidants (20).

In this study ascorbic acid was decreased in diabetes mellitus and this may be due to renal reabsorption of vitamin C,may be reduced by hyperglycemia, blood glucose may compete with vitamin $\mathrm{C}$ for uptake into certain cells and tissues, cellular regulation of vitamin $\mathrm{C}$ may be impaired, and increased oxidative stress may deplete antioxidant reserves. (21). And the lower levels of vitamin $\mathrm{C}$ in diabetes mellitus type with nephropathy may be due to an increased renal excretion of this vitamin (22).

In this study catalase enzyme was decreased in diabetes mellitus and this may be due to oxidative stress involved in the origin of type 1 diabetes, low efficiency of the scavenging antioxidant system has been shown to be related to the pathogenesis of the disease this, therefore suggests that genes encoding catalase and other antioxidant enzymes may implicate in the development of type 1 diabetes (23).

The negative correlation between plasma total antioxidant capacity and oxidative damage suggests a correlation in this pathological condition. It may also be possible that metabolic disturbs in diabetic patients, including missing antioxidants, result in a major oxidation. High oxidative insult and missing antioxidants may be concurrent in the diabetic patient (24).

In this study the un change in the activity of aldolase enzyme in diabetic red cells can only be explained on the basis of possible altered partitioning of this enzyme between the cytoplasmic and membrane bound fractions inside the diabetic red cell (25). 
In this study the increased activities of pyruvate kinase enzyme in diabetic patients may be due to a greater proportion of young erythrocytes because of a shortened red cell life span as compared to normal. (26)

\section{Conclusion:}

Ascorbic acid, Catalase,Aldolase and Pyruvate kinase enzymes can be used to differentiate between diabetes mellitus type 1 and diabetes mellitus type 1 with nephropathy.

Total antioxidant capacity can not be used to differentiate between diabetes mellitus type 1 and diabetes mellitus type 1 with nephropathy.

The antioxidant and enzymes also can be used to follow up in patients suffering from diabetes mellitus type 1 and predict other complications.

\section{References:}

1. Trivedi, B, Mazumdar, J D, Bhatt and Hemavathi $K \boldsymbol{G}$. 2004: Effect of Shilajit on blood glucose and lipid profile in alloxan-induced diabetic rats, Indian J Pharmacol; 36(6): 373-376.

2. $\quad$ M Malandrino and $\boldsymbol{R} \boldsymbol{J}$ Smith,2011: Personalized medicine in diabetes, Clinical Chemistry; 57( 2):231-240.

3. Angela D Liese, Robin C Puett, Archana P Lamichhane, Michele D Nichols, Dana Dabelea, Andrew B Lawson, Dwayne E Porter, James D Hibbert, Ralph B D'Agostino Jr and Elizabeth $J$ Mayer Davis, 2012: Neighborhood level risk factors for type 1 diabetes in youth.International, Journal of Health Geographics;11:1-9.

4. Ikegami H, Awata T, Kawasaki E, Kobayashi T, Maruyama T, Ogihara T, et al., 2006: The association of CTLA4 polymorphism with type 1 diabetes is concentrated in patients complicated with autoimmune thyroid disease a multicenter collaborative study in Japan, J Clin Endocrinol Metab.;91:1087-92.

5. Themis Zelmanovitz, Fernando Gerchman, Amely PS Balthazar, Fúlvio CS Thomazelli, Jorge $D$ Matos, and Luís $H$ Canani., 2009:Diabetic nephropathy.Diabetology \& Metabolic Syndrome;1:10.

6. MacIsaac RJ, Tsalamandris C, Panagiotopoulos S, Smith TJ, McNeil KJ, Jerums G., 2004: Nonalbuminuric renal insufficiency in type 2 diabetes, Diabetes Care;27:195-200.

7. Li Y and Schellhorn HE., 2007 :New developments and novel therapeutic perspectives for vitamin C,J Nutr.;137:2171-84.

8. McGregor.GP and Biesalski, HK., 2006: Rationale and impact of vitamin $\mathrm{C}$ in clinical nutrition, Current opinion in clinical nutrition and metabolic care; 9 (6): 697-703.

9. Cunningham JJ., 1998 :The glucose/insulin system and vitamin $\mathrm{C}$ : implications in insulindependent diabetes mellitus,J Am Coll Nutr.;17(2):105-8.

10. Chelikani P, Fita I, Loewen PC., 2004:Diversity of structures and properties among catalases, Cell. Mol. Life Sci.; 61 (2): 192-208.
11. Scibior D and Czeczot H., 2006: Catalase: structure, properties, functions.Article in Polish.Zakład Biochemii Akademii Medycznej w Warszawie Postepy ,Hig Med Dosw;60:170-80.

12. Bargagli R., 2000:Trace metals in Antarctica related to climate change and increasing human impact,Rev Environ Contam Toxicol.;166:129173.

13. Motherwell W B, Bingham M J, Six Y., 2001: Studies Towards Novel Aldolase Mimics .Tetrahedron;57: 4663.

14. Voet, Donald, Judith G Voet, and Charlotte $W$ Pratt, 2008: Fundamentals of Biochemistry: Life at the Molecular Level, Hoboken NJ: John Wiley \& Sons, Inc;3: 501-503.

15. kholoud s ramadan and khaled $z$ el karmouty, 2009: evaluation of oxidative stress and cardiovascular disease risk factors in type ii diabetic postmenopausal women. report and opinion;1(1):79-90.

16. Koracevic D, Koracevic G, et al., 2001: A colorimetric method for the determination of total antioxidative capacity activity, J . Clin . Pathol.; 54: 356-361 .

17. Young D S., 2000:Effect of drug on clinical lab.test.AACC press.:5.

18. Sies and Helmut, 1997:Oxidative stress: Oxidants and antioxidants, Experimental physiology; 82 (2): 291-5.

19. Marilena Kampa, Anastasia Nistikaki, Vassilios Tsaousis, Niki Maliaraki, George Notas, and Elias Castanas, 2002:A new automated method for the determination of the Total Antioxidant Capacity (TAC) of human plasma, based on the crocin bleaching assay ,BMC Clin Pathol.; (2)2: 3.

20. Julie $C$ Will, Earl $S$ Ford, and Barbara $A$ Bowman , 1999:Serum vitamin C concentrations and diabetes: findings from the third National Health and Nutrition Examination Survey, AmJ Clin Nutr .;70:49-52.

21. Ndahimana J, Dorchy H, Vertongen F .,1996: Erythrocyte and plasma antioxidant activity in diabetes mellitus type I,Presse Med.;25(5):188-92.

23. Chistiakov DA, Savost'anov KV, Turakulov RI, Titovich EV, Zilberman LI, Kuraeva TL, Dedov II, Nosikov VV., 2004 :A new type 1 diabetes susceptibility locus containing the catalase gene (chromosome 11p13) in a Russian population,Diabetes Metab Res Rev.;20(3):219-24.

24. J V Caldero'n Salinas, E. G. Muñoz Reyes, J. F. Guerrero Romero, M. Rodri' guez Mora'n, R. L. Bracho Riquelme $M$ A, Carrera-Gracia $M$ A,Quintanar Escorza, 2011:Eryptosis and oxidative damage in type 2 diabetic mellitus patients with chronic kidney disease ,Mol Cell Biochem ;357:171- 179.

25. SI Rizvi MA Zaid M Suhail, 1996.:Erythrocyte Aldolase in Type I (Insulin-dependent) Diabetes mellitus ,Bioved;7(1):29-33.

26. Suhail $M$ and Rizvi S., 1989: Effect of type I (insulin-dependent) diabetes mellitus on key glycolytic enzymes of red blood cells,Acta Diabetol Lat.;26(4):315-20. 


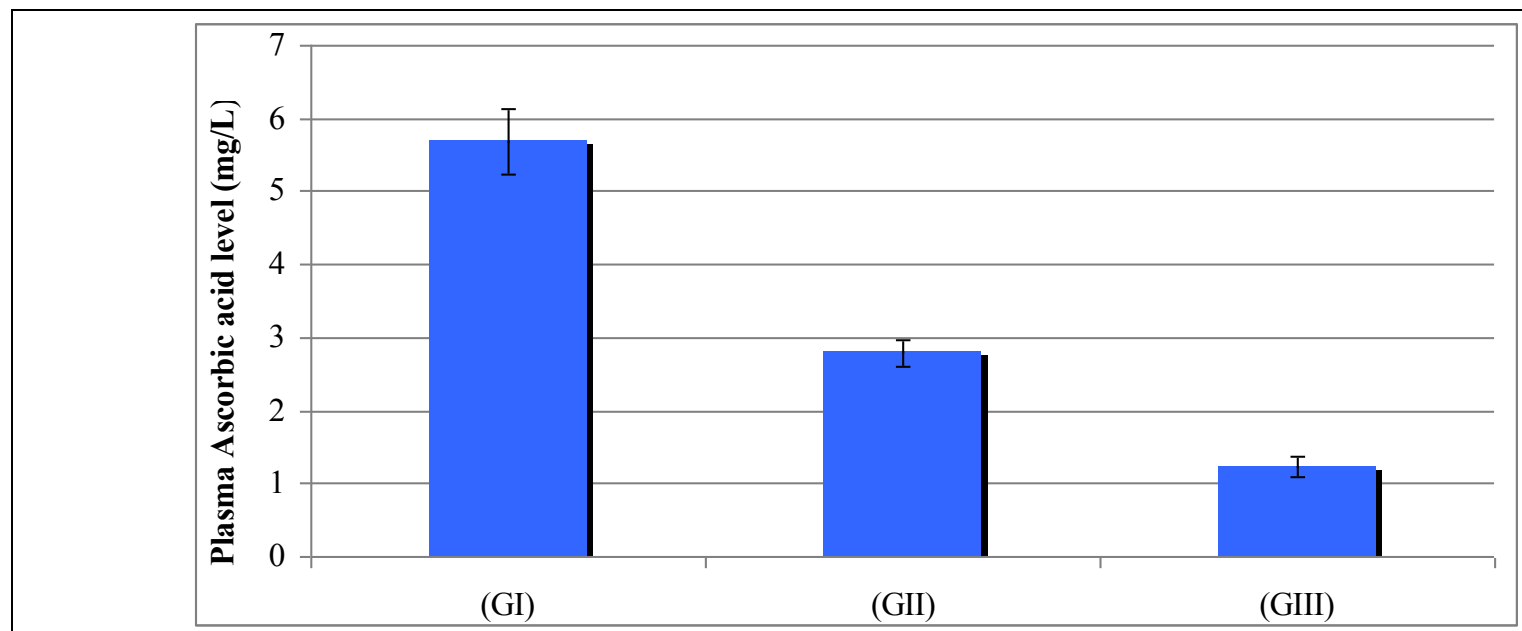

Fig. 1: Means of plasma Ascorbic acid level (mg / L) in control group and different studied groups.

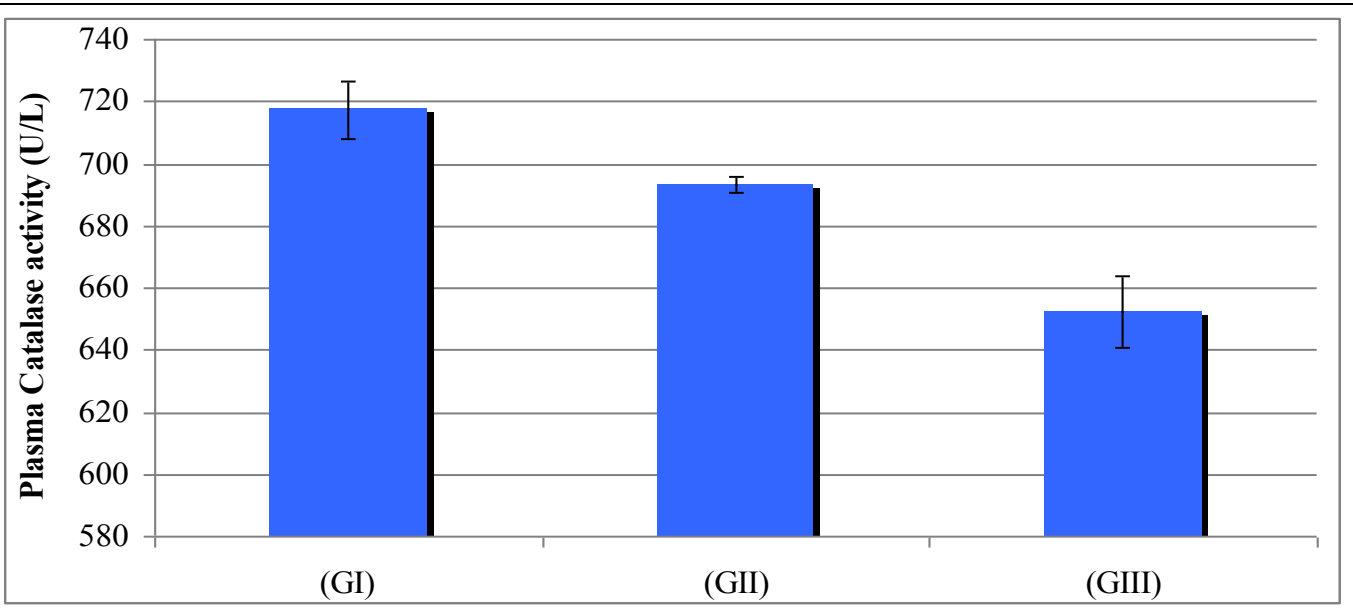

Fig. 2: Means of plasma Catalase activity (U/ L) in control group and different studied groups.

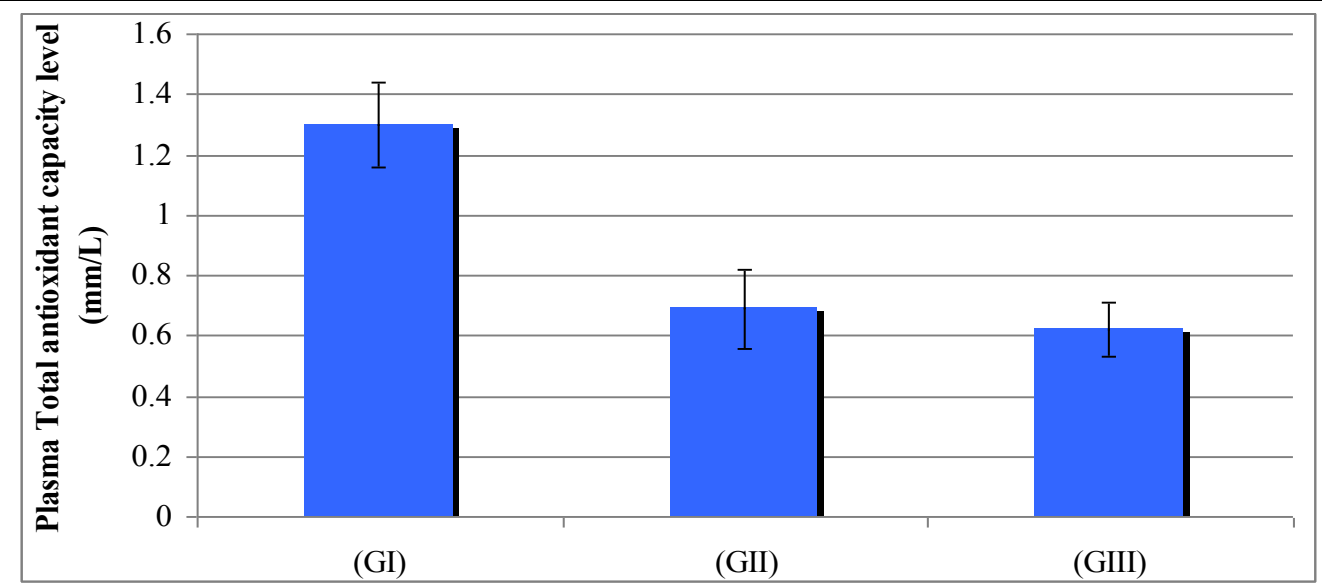

Fig. 3: Means of plasma Total antioxidant capacity $(\mathrm{mM} / \mathrm{L})$ in control group and different studied groups. 
M.El-desoky et al

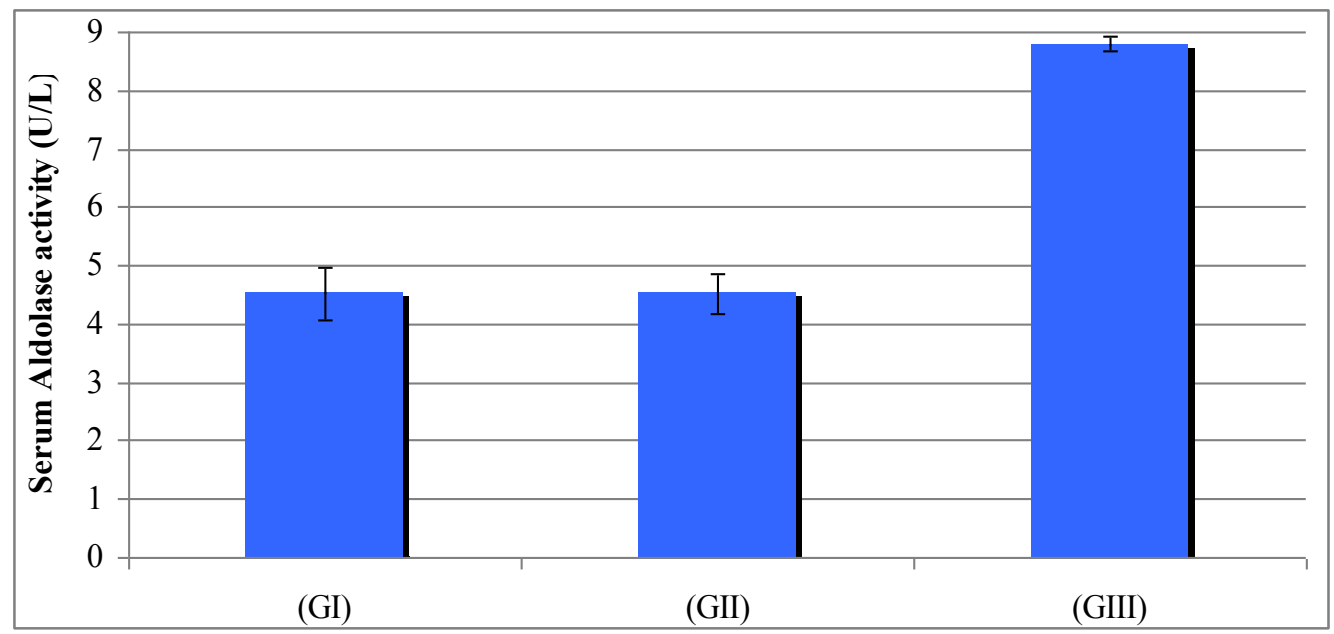

Fig. 4: Means of serum aldolase activity $(\mathrm{U} / \mathrm{L})$ in control group and different studied groups.

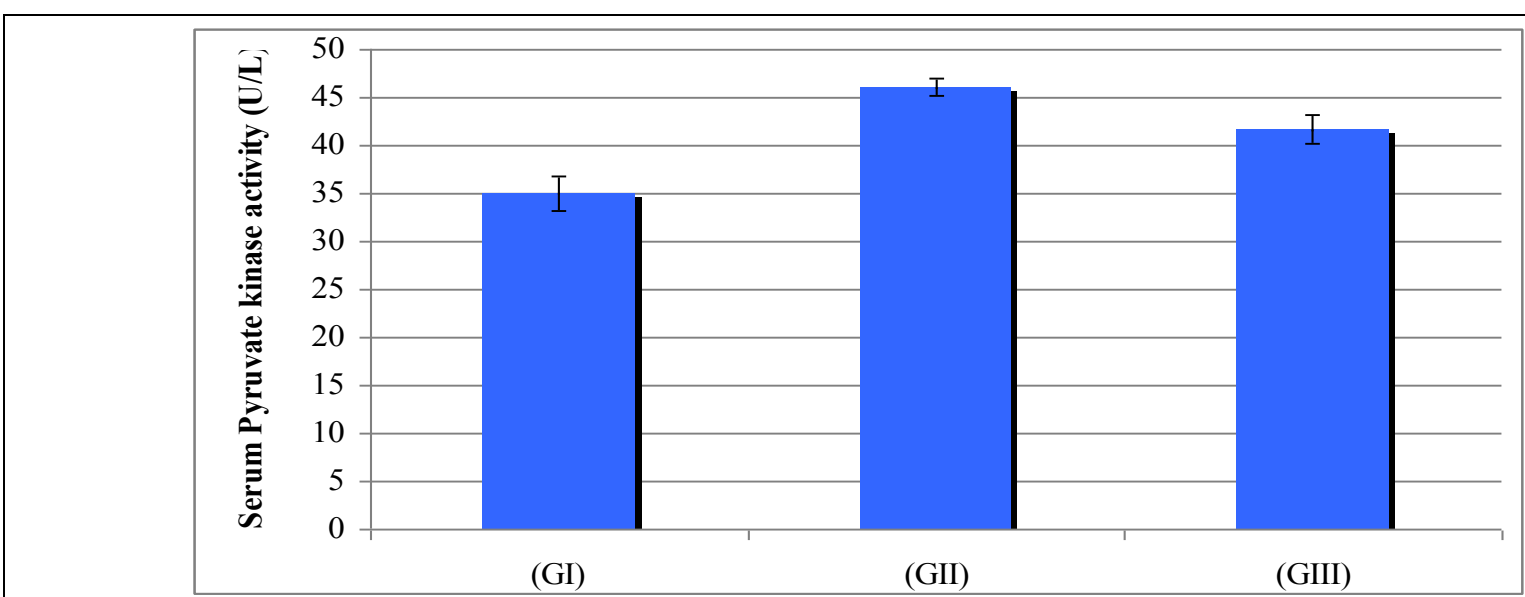

Fig. 5: Means of serum pyruvate kinase activity (U/L) in control group and different studied groups. 